\title{
Clinical study of the patients with intractable temporomandibular disorders intervened with psychologic problems
}

\author{
Dong-Woo Kang ${ }^{1}$, Young-Kyun Kim ${ }^{1,2 *}$ \\ ${ }^{1}$ Department of Oral and Maxillofacial Surgery, Section of Dentistry, Seoul National University Bundang Hospital, Seongnam, Korea \\ ${ }^{2}$ Department of Dentistry and Dental Research Institute, School of Dentistry, Seoul National University, Seoul, Korea
}

This study was carried out to evaluate the clinical treatment and prognosis of patients with the refractory temporomandibular disorder (TMD) with mental problems. The study included 27 patients with the TMD with mental problems from the Seoul National University Bundang Hospital, South Korea, between June 2003 and December 2016 (8 males, 19 females, mean age 40.9 years). Diagnosis of TMD disorder was made based on history, clinical examination, RDC/TMD chart, and radiologic examination (panorama, T-M panorama, CT, scintigraphy, MRI). RDC/TMD Axis II was used to discriminate between the presence and absence of a mental problem. The age, sex, chief complaint, diagnosis, treatment method, duration and prognosis of the patients were analyzed and the progress of treatment was analyzed using RDC/TMD Axis II. The number of female patients was higher than that of male patients (19 females, 8 males) and the majorities (51.9\%) of them were middle-aged patients (over 40 years). Treatment methods selectively included taking medications such as analgesics and antidepressants, splint devices, physical therapy, TMJ injection, botulinum injection, trigger point anesthesia injection, arthrocentesis, and arthroscopy. Co-treatment was done in departments of neuropsychiatry, rehabilitation medicine, neurology, and anesthesiology, if necessary. The mean duration of treatment was 38.8 months. Improvement in prognosis was observed in 17 cases, no difference was noted in 7 cases and the worse prognosis was observed in 3 cases. When active psychosocial support and psychiatric treatment in addition to TMJ treatment were performed, patients with refractory TMJ disorders and mental problems exhibited favorable prognosis.

Key Words: Temporomandibular disorder, Research diagnostic criteria for temporomandibular disorders, Psychotic disorders

(c) This is an open-access article distributed under the terms of the Creative Commons Attribution Non-Commercial License (http://creativecommons.org/licenses/by-nc/4.0) which permits unrestricted noncommercial use, distribution, and reproduction in any medium, provided the original work is properly cited.

\section{서 론}

턱관절장애(temporomandibular disorders, TMD)는 저작 근, 턱관절과 주변 관련 구조들에 발생하는 임상적인 문제를 포 괄하는 근골격성 및 신경근육성 질환을 의미한다[1]. 주로 나타 나는 $\mathrm{TMD}$ 증상은 통증, 청각적인 문제, 턱기능의 불편감, 구강 안면통증, 두통 등을 들 수 있다. 턱관절장애의 원인은 보통 다
인성인 경우가 많고, 증상을 유발시키기도 하고 증상을 지속시 키는 요인이 되기도 하며, 질병의 결과인 부산물로 나타나기도 한다.

턱관절의 증상은 근육 문제, 외상, 미세 외상, 비정상적인 구 강 기능습관, 심리적 스트레스 등의 심리학적 혹은 생리적인 요 소들이 복합적으로 작용하여 다양하게 나타난다[2,3]. 이 중 정 신, 심리적인 문제가 연관된 경우에는 통증 외에도 피로감, 이

Received May 29, 2018; Revised July 20, 2018; Accepted August 6, 2018

Corresponding author: Young-Kyun Kim, Department of Oral and Maxillofacial Surgery, Section of Dentistry, Seoul National University Bundang Hospital, 82 Gumi-ro 173beon-gil, Bundang-gu, Seongnam 13620, Korea.

Tel: +82-31-787-7541, Fax: +82-31-787-4068, E-mail: kyk0505@snubh.org

Copyright $\odot$ 2018, Oral Biology Research Institute 
상 불쾌감 등 표현하기 곤란한 다수의 증상들이 나타나며 통증 의 유형은 체성통증(somatic pain)이 아니라 신경병변성 통증 (neuropathic pain) 또는 심리적인 통증(psychogenic pain) 이 많다[4]. 난치성 턱관절장애환자가 사회적 기능을 수행하 면서 겪는 정서적, 심리적 스트레스, 불안, 좌절, 공포 등에 대 한 개인적, 사회적인 적응 과정의 관계를 평가하는 것이 필요하 다. 호소하는 통증에 관해 보다 명확한 정보를 얻기 위해서 통 증에 관한 biopsychosocial model을 만들어 조사하는 것이 필 요하다[5]. 이는 생리적인 요소와는 별개로 질병과 관련된 심리 적/사회적 요인을 포함한 것으로 1992년에 만들어진 Research Diagnostic Critera for Temporomandibular Disorders (RDC/ TMD) Axix II를 통해 진단을 내리는 데 도움이 된다[6,7].

턱관절장애의 치료는 환자의 상태를 정확하게 평가하고 진단 을 내린 후 치료법을 결정하는데 흔히 상담치료, 약물치료, 물리 치료, 운동요법, 행동요법, 장치치료 등의 보존적인 치료법과 교 합치료, 외과적 치료 등의 비가역적인 치료로 나눌 수 있다. 여 기에 정신과적인 문제가 동반되어 치료가 복잡해지는 경우는 신경과, 정신건강의학과, 마취통증의학과 등과 협의하여 협진 하는 것이 필요하다.

턱관절의 보존적인 치료방법은 효과가 있는 것으로 알려 져 있는데, 그 중 교합안정장치는 임상적으로 매우 유용하 게 사용되고 있다[8,9]. 교합안정장치는 치아의 마모와 동요 를 방지하고, 균등한 치아 접촉을 부여하여 교합관계를 정상 화시키고, 교합력을 재분산시켜 턱관절의 안정화, 저작근 통 증과 기능장애를 치료하는 효과가 있다. 또한, 이갈이와 이 상기능을 감소시키며 근육의 긴장도 감소에도 효과가 있 다. Clark [10]은 교합안정장치의 작용기전을 비정상 교합 접촉의 해소론(occlusal disengagement theory), 교합고경 변화론(vertical dimension theory), 상하악관계 재배열론 (maxillomandibular realignment theory), 측두하악관절 재위 치론(temporomandibular joint repositioning theory), 인지론 (cognitive awareness theory) 등으로 설명하고 있다.

약물치료(pharmacotherapy)도 턱관절장애 치료에 효과적으 로 사용되고 있는 방법이다[11]. 흔히 비스테로이드성 소염진통 제의 단기 투여, 비특이성 통증을 위한 항우울제와 항경련제의 장기 투여가 효과가 좋으며, 보조적으로 근육이완제, 삼환계 항 우울제, 코티코스테로이드, 국소마취제 등이 많이 사용되고 있 다[12]. 근이완제는 벤조디아제핀 혹은 싸이클로벤자프린 등이 사용되며, 근육이완, 수면 개선에 효과가 있다.

물리치료(physical therapy)도 턱관절의 보존적인 치료로 효 과적이다. 종류로는 냉각제분사(vapocoolant spary)요법, 온 열 요법, 전기요법(electrotherapy), 초음파 치료(ultrasound), 이온삼투요법(iontophoresis), 침술(acupuncture), 발통점 주 사(trigger-point injections), 레이저 치료(laser therapy), 오 존 치료(ozonytron therapy) 등이 있다. 전기요법은 직류전 기성자극(electrogalvanic stimulation)과 경피성신경자극 (transcutaneous electrical nerve stimulation, TENS) 등이 있 으며 통증 감소, 혈류를 증가시켜 부종 감소 효과, 근경련의 완 화에 도움이 된다[13]. 이온 삼투 요법은 약물 이온들의 조직장 벽을 넘어 운반량을 증가시키는 방법으로, 주로 코티코스테로 이드를 이용한다. 발통점 주사 요법은 근막 통증의 치료에 효 과가 있으며 마취제에 의한 통증 감소와 함께 주사바늘에 의한 발통점의 기계적인 파괴로도 치료 효과가 있는 것으로 생각된 다[14,15]. 오존 요법은 관절강 내 오존 가스가 물을 통해 거품 이 일고 혼합물이 관절강 사이로 직접 주입되어 관절염, 류마 티즘 등의 치료에 이용된다. 주로 쿠바, 러시아, 독일의 의사들 이 사용했으며 턱관절에 발생하는 세균, 바이러스, 진균 등의 감 염에 의한 이차적인 염증을 줄이고, 신생 연골 증식을 자극시키 는 효과가 있다[16,17]. Botulinum toxin type A의 주입은 근수 축 자극을 억제하여 저작 근육을 포함한 구강 기능성 악습관을 조절하는데 도움을 주며, 그에 따라 턱관절에 가해지는 과부하 를 줄일 수 있다[18]. 관절강 내 주사요법에는 히알루론산 혹은 platelet-rich plasma를 주로 사용하는데, 히알루론산은 관절 강 내 항상성을 유지하는데 도움을 준다. 즉, 히알루론산은 윤활 액(synovial fluid)의 탄성과 점성을 부여해 충격을 완충하는 역 할을 해주고 연골에서 조직 회복을 활성화 해주고 윤활, 항염증, 통증완화에 도움을 준다[19,20]. 턱관절세정술(arthrocentesis) 은 대부분의 관절강 내의 염증성 산물 및 유발물질들을 제거하 고 유착된 조직들을 유리시켜 턱관절 질환의 예방 및 치료에 우 수한 효과를 보이며 성공률도 $90 \%$ 이상으로 매우 높은 것으로 알려져 있다[21-23].

본 연구는 난치성 턱관절장애를 가진 환자들 중 정신적 문제 가 동반된 환자들의 임상적 치료과정 및 치료 예후를 평가하여 효과적인 치료 방법과 연구 방법을 모색하고자 한다.

\section{대상 및 방법}

2003년 6월부터 2016년 12월까지 턱관절장애 진단 하에 분 당서울대학교병원 구강악안면외과에서 진료받은 환자들 중 정 신적인 문제가 동반된 27 명의 환자들을 연구 대상으로 하였 다. 8 명의 남성, 19 명의 여성이었으며, 평균 연령은 40.9세였 다. 모든 환자들은 분당서울대학교병원이나 다른 병·의원의 정 신건강의학과 진료를 받는 환자들이었다. 턱관절장애의 진단학 적 방법으로는 병력 청취, 임상 검사, RDC/TMD chart, 영상의 학적 검사(파노라마, 턱관절 파노라마 방사선 사진, computed tomography, scintigraphy, magnetic resonance imaging) 
를 활용하였다. 해당 환자들의 나이, 성별, 주소, 진단, 치료방법 및 기간, 예후 등을 조사하여 분석하였다. 치료 방법으로는 진 통제, 항우울제 등의 약물치료와 교합안정장치(splint) 치료, 레 이저, ozonytron, Electro-Acupuncture Stimulation Therapy (EAST) 등의 물리치료, 관절강 주사(hyaluronic acid, steroid), 보툴리눔톡신 주사, 발통점 주사, 턱관절세정술 혹은 턱관절내 시경수술 등을 단독 혹은 복합적으로 시행하였다. 환자에 따라 필요 시 정신건강의학과, 재활의학과, 신경과, 마취통증의학과 등과 협진하여 병행치료를 시행하기도 하였다. 재활의학과는 교통사고, 외상 등의 후유증으로 턱관절 치료가 장기화 되는 경 우에 더 심도 있는 물리치료를 위해 협진을 하였고, 턱관절 통증 과 함께 신경통을 호소하는 환자는 마취통증의학과와 협진하여 stellate ganglion block를 시행하기도 하였다.

치료 경과는 턱관절이나 부수적인 안면 통증, 전신통증, 두 통 등의 통증의 증감 유무, 개구제한의 개선 정도, 환자의 주관 적인 반응 등을 토대로 분석하였다. Poor (증상이 악화된 경우), Static (증상의 변화가 없는 경우), Good (증상이 개선된 경우) 의 세 가지로 분류하였다[24,25].

9명의 환자에게서 설문지를 이용하여 RDC/TMD Axis II 검 사법을 시행하였다. 검사 내용 및 계산방법은 다음과 같다[26] (Supplementary material; available online only).

\section{만성통증척도(Graded Chronic Pain Scale, GCPS)}

Graded pain score: Grade 0 (최근 6개월간 통증 없었을 경 우), I, II, III, IV (Table 1)

Characteristic pain intensity: $\mathrm{RDC}$ 의 7, 8, 9 문항에 표기한 visual analog scale (VAS) 크기의 평균 $\times 10$

Disability point: Disability days (0-3)+Disability score $(0-3, \mathrm{RDC}$ 의 $11,12,13$ 문항에 표기한 $\mathrm{VAS}$ 크기의 평균 $\times 10)$ (Table 2)

\section{턱관절장애로 인해 느끼는 심리적 고통의 정도(Depression scale)}

환자들의 심리적 고통은 설문지 20 번 질문의 우울증 지수를 평가하는 항목 $(2,5,6,7,8,9,11,12,13,14,17,22,25,26$, $27,28,29,30,31,32)$ 에 답한 수치(0-4)를 합한 후 평균을 구 하여 심도에 따라 normal, moderate, severe의 3 단계로 분류 하였다. 또한, 각 진단군에서 설문 내용의 세부적인 항목에 따른 증상을 호소하는 정도를 조사하였다(Table 3). 그 항목으로는 성욕상실, 기력이 감소하거나 처진 느낌, 죽음에 대한 생각이나 죽어간다는 생각, 식욕감소, 쉽게 울음, 자책감, 외로움, 우울감,
지나친 걱정, 흥미 상실, 잠들기 어려움, 미래에 대한 절망감, 죽 고 싶다는 느낌, 과식, 아침 일찍 잠이 깸, 잠자리가 불편하거나 방해 받음, 모든 것이 힘들다는 느낌, 무의미하다는 느낌, 갇혀 있거나 잡혀 있다는 느낌, 죄의식 같은 것들이 있다.

Table 1. Graded chronic pain score

\begin{tabular}{ll}
\hline \multicolumn{1}{c}{ Grade } & \multicolumn{1}{c}{ Pain score } \\
\hline Grade 0 & $\begin{array}{l}\text { No pain and TMD in past 6 } \\
\text { months }\end{array}$ \\
Low disability & $\begin{array}{l}\text { Characteristic pain intensity }<50, \\
\text { disability point }<3\end{array}$ \\
Grade I: low intensity & $\begin{array}{l}\text { Characteristic pain intensity } \geq 50, \\
\text { disability point }<3\end{array}$ \\
Grade II: high intensity & \\
High disability & $\begin{array}{l}\text { Disability point 3-4 } \\
\text { (characteristic pain intensity } \\
\text { unrelated) }\end{array}$ \\
Grade IV: severely limiting & $\begin{array}{l}\text { Disability point 5-6 } \\
\text { (characteristic pain intensity } \\
\text { unrelated) }\end{array}$ \\
\hline
\end{tabular}

TMD, temporomandibular disorder.

Table 2. Disability points

\begin{tabular}{lccc}
\hline & $\begin{array}{c}\text { Disability days } \\
(\mathbf{0}-\mathbf{1 8 0})\end{array}$ & $\begin{array}{c}\text { Disability } \\
\text { score }(\mathbf{0}-\mathbf{1 0 0})\end{array}$ \\
\hline 0-6 days & 0 & $0-29$ & 0 \\
7-14 days & 1 & $30-49$ & 1 \\
15-30 days & 2 & $50-69$ & 2 \\
Over 30 days & 3 & Over 70 & 3 \\
\hline Disability point $(0-6):$ disability days $(0-3)+$ disability score $(0-3)$.
\end{tabular}

Table 3. Depression scale, nonspecific physical symptom score

\begin{tabular}{lccc}
\hline \multicolumn{1}{c}{ Psychological distress } & Normal & Moderate & Severe \\
\hline Depression scale & $<0.535$ & $0.535-1.105$ & $\geq 1.105$ \\
$\begin{array}{c}\text { Nonspecific physical symptom } \\
\text { (pain items include) }\end{array}$ & $<0.500$ & $0.500-1.000$ & $\geq 1.000$ \\
$\begin{array}{c}\text { Nonspecific physical symptom } \\
\text { (pain items exclude) }\end{array}$ & $<0.428$ & $0.428-0.857$ & $\geq 0.857$ \\
\hline
\end{tabular}




\section{각 진단군의 체성화(비특이성 신체증상)로 인한 고통 (Nonspecific physical symptom score)}

체성화로 인한 고통은 설문지 20번 질문의 비특이성 신체증 상에 대한 내용 중 통증항목을 포함(1, 3, 4, 10, 15, 16, 18, 19, $20,21,23,24)$ 하여 조사하였고(Table 3), 답한 수치(0-4)의 평 균을 구하여 심도에 따라 normal, moderate, severe의 3단계로 분류하였다. 또한, 각 진단군에서 세부적인 항목에 따른 정도를 조사하였으며 그 항목으로는 두통, 현기증, 흥통, 허리 뒤의 통 증, 메스꺼움, 근육통, 호흡곤란, 체온 이상, 신체감각 이상, 경 부 종창감, 허약감, 무거운 느낌 등이다.

\section{각 진단군의 일상 생활 중 지장을 느끼는 정도(하악 기능과 관련된 기능제한) (Functional limitation concerned to mandible movement, FL)}

설문조사 내용의 19 번 문항(씹기, 마시기, 이닦기나 세수하 기, 운동하기, 하품하기, 딱딱한 음식 먹기, 음식물 삼키기, 부드 러운 음식 먹기, 말하기, 미소 짓기나 웃기, 평상시 얼굴 표정 짓 기)에서 각 항목에 대하여 불편함을 느끼는지 여부를 조사하였 다. 환자들은 '예, 아니오'로만 대답하였으며 그 정도는 조사하 지 않았다.

본 연구는 분당서울대학교병원 생명연구윤리심의위원회 (Institutional Review Board, IRB)의 승인(IRB no. B-1802450-101)하에 시행되었다.

\section{결 과}

27 명의 연구 대상 환자들의 평균 관찰 기간은 38.8 개월 이었 다. 여성 환자가 19명(70.4\%)으로 남성환자인 8명(29.6\%)보다 많았으며, 40 세 이상의 중장년 층의 환자들의 비율이 $51.9 \%$ 로

Table 4. Distribution of age and sex

\begin{tabular}{cccc}
\hline Age $(\mathbf{y})$ & Male & Female & Total \\
\hline $10-19$ & 1 & 1 & 2 \\
$20-29$ & 2 & 2 & 4 \\
$30-39$ & 3 & 4 & 7 \\
$40-49$ & 2 & 3 & 5 \\
$\geq 50$ & 0 & 9 & 9 \\
Total & 8 & 19 & 27 \\
\hline
\end{tabular}

Values are presented as number.
상대적으로 많았다(Table 4). 환자들이 호소하는 불만과 증상은 턱관절 통증, 두통, 턱관절 잡음, 부정교합, 개구제한, 목 및 어 깨 통증, 이갈이, 이악물기, 저작 시 불편감, 귀 통증, 전신적 통 증이나 무력감, 개구 시 $\mathrm{S}$ 자 변위, 교근 통증 등 매우 다양한 증 상 등이 있었다(Table 5). 이 외에도 안면 비대칭, 코뼈와 입천 장이 조이는 느낌, 발열, 턱관절 부종, 치통, 불면증 등의 증상도 호소하였다. 진단은 관절성 병변, 근육성 병변, 복합 병변의 3 가 지 그룹으로 분류하였다(Table 6).

치료는 다른 턱관절장애 환자들과 마찬가지로 상담, 투약, 물 리치료, 스프린트 치료 등과 같은 보존적인 처치만으로도 효과 가 있는 경우가 많았으며, 대체로 2가지 이상의 복합된 치료가 대부분이었다(Table 7). 기본적인 치료(상담, 약물치료)만 사 용한 경우가 3증례, 기본적인 치료와 물리치료(레이저, EAST, Ozonytron 등)를 병행한 경우가 1증례, 기본적인 치료와 스프 린트 치료를 사용한 경우가 6증례 있었다. 기본적인 치료와 물 리치료, 장치치료를 병행한 경우가 7증례, 기본적인 치료와 물 리치료, 스프린트 치료, 관절강 내 주사 치료를 시행한 경우가 4증례, 기본적인 치료와 물리치료, 스프린트 치료, 보툴리눔톡 신 주입을 시행한 경우가 1증례, 기본적인 치료, 물리치료, 스 프린트 치료, 발통점 주사를 시행한 경우가 1증례, 기본적인 치 료, 물리치료, 스프린트 치료, 관절강 내 주사, 보툴리눔톡신 치 료를 병행한 경우가 3 증례, 기본적인 치료, 물리치료, 스프린트 치료, 관절강 내 주사, 보툴리눔톡신 치료, 턱관절 내시경 수술

Table 5. Types of symptoms and complaints

\begin{tabular}{lc}
\multicolumn{1}{c}{ Type } & Number \\
\hline TMJ pain & 16 \\
Headache & 16 \\
TMJ noise & 13 \\
Malocclusion & 7 \\
Mouth opening limitation & 7 \\
Pain of neck or shoulder & 4 \\
Bruxism or clenching & 4 \\
Discomfort of mastication & 3 \\
Pain in ear & 3 \\
Systemic pain or fatigue & 3 \\
S-deviation in mouth opening & 2 \\
Pain of masseter muscle & 2 \\
Others & 8 \\
\hline
\end{tabular}

TMJ, temporomandibular joint. 
Table 6. Distribution of diagnosis

\begin{tabular}{lcc}
\multicolumn{1}{c}{ Diagnosis } & Number & Percentage \\
\hline Arthrogenous group & 12 & 44.4 \\
Myogenous group & 6 & 22.2 \\
Combined group & 9 & 33.3 \\
Total & 27 & 100 \\
\hline
\end{tabular}

Table 7. Distribution of treatment types

\begin{tabular}{lc}
\hline Treatment & Number \\
\hline $\mathrm{A}$ & 3 \\
$\mathrm{~A}+\mathrm{B}$ & 1 \\
$\mathrm{~A}+\mathrm{C}$ & 6 \\
$\mathrm{~A}+\mathrm{B}+\mathrm{C}$ & 7 \\
$\mathrm{~A}+\mathrm{B}+\mathrm{C}+\mathrm{D}$ & 4 \\
$\mathrm{~A}+\mathrm{B}+\mathrm{C}+\mathrm{E}$ & 1 \\
$\mathrm{~A}+\mathrm{B}+\mathrm{C}+\mathrm{F}$ & 1 \\
$\mathrm{~A}+\mathrm{B}+\mathrm{C}+\mathrm{D}+\mathrm{E}$ & 3 \\
$\mathrm{~A}+\mathrm{B}+\mathrm{C}+\mathrm{D}+\mathrm{E}+\mathrm{G}$ & 1
\end{tabular}

A: basic therapy (counseling+medication), B: physical therapy (laser, Electro-Acupuncture Stimulation Therapy, ozonytron), C: splint, D: joint injection, E: Botulinum toxin type A injection, F: trigger point injection, G: arthroscopy.

을 시행한 경우가 1 증례 있었다. 치료 경과는 증상이 개선된 경 우가 17명(63.0\%)을 보였고, 나머지 10명(37.0\%)은 개선이 되 지 않았거나 악화된 경우도 있었다(Table 8). 정신건강의학과, 재활의학과, 신경과, 마취통증의학과 등에 협진을 의뢰를 요청 한 비율은 59.3\% (16/27명)였다. 구강악안면외과에서만 진료 를 받은 환자들과 타과 협진을 받은 환자들을 비교했을 때 좋은 예후를 보인 환자들 중 $58.8 \%$ (10/17명)가 협진을 받은 환자였 다(Table 9). 9명의 환자에게서 RDC/TMD Axis II를 분석하였 다(Table 10). 1) GCPS는 grade 0에서 IV 중에 평균 grade 3.4 로 나왔고, 2) Depression scale (D)는 severe한 경우가 5명, moderate한 경우가 3명, normal한 경우가 1명으로 나왔다. 3) Nonspecific physical symptoms: somatization score, pain items included는 severe한 경우가 6명, moderate한 경우가 3 명 있었고, 4) Nonspecific physical symptoms: somatization score, pain items excluded는 severe한 경우가 3명, moderate 한 경우가 4명, normal이 2명 있었다. 5) FL은 0에서 1점 중 평 균 0.61 로 나타났다.
Table 8. Progress of treatment

\begin{tabular}{ccc}
\hline Progress & Number & Percentage \\
\hline Poor & 3 & 11.1 \\
Static & 7 & 25.9 \\
Good & 17 & 63.0 \\
Total & 27 & 100 \\
\hline
\end{tabular}

Table 9. The number of Co-treatment

\begin{tabular}{ccc}
\hline Progress & Co-treatment & OMFS \\
\hline Poor & $1(6.2)$ & $2(18.2)$ \\
Static & $5(31.3)$ & $2(18.2)$ \\
Good & $10(62.5)$ & $7(63.6)$ \\
Total & $16(100)$ & $11(100)$ \\
\hline
\end{tabular}

Values are presented as number (\%).

Co-treatment: treatment with dental clinic and other departments. OMFS: only treatment in Oral and Maxillofacial surgery.

Table 10. Analysis of RDC/TMD Axis II

\begin{tabular}{cl}
\hline RDC/TMD & \multicolumn{1}{c}{ Scale } \\
\hline 1 & Grade 3.4 (grade 0-IV) \\
2 & Severe 5, moderate 3, normal 1 \\
3 & Severe 6, moderate 3 \\
4 & Severe 3, moderate 4, normal 2 \\
5 & $0.61(0-1)$ \\
\hline
\end{tabular}

1: graded chronic pain scale (GCPS), 2: depression scale (D), 3: nonspecific physical symptoms: somatization score, pain items included (NPSI), 4: nonspecific physical symptoms: somatization score, pain items excluded (NPSE), 5: functional limitation concerned to mandible movement (FL).

\section{고 찰}

턱관절장애 환자들 중에 정신적 인자가 증상에 깊게 관여하 는 경우가 종종 있다. 스트레스, 걱정, 불안과 관련된 심리적인 장애는 구강안면의 parafunctional activity를 촉진하여 턱관절 장애를 발현시키거나 심화 시킬 수 있다. 대개 불안, 긴장, 강박 증, 우울증, 신경증, 심기증, 신체화증상 등의 경향을 보이는 것 으로 알려져 있는데, Schwartz 등[27]은 정서적 갈등과 신체화 증상을 보고한 바 있다. Celic 등[28]은 턱관절장애 환자에서 우 울 척도, 신체화 척도가 상승되어 나왔다는 연구 결과도 있다. 본 연구에서도 정신적 질환을 가진 턱관절 환자들은 매우 다양 
한 증상들을 호소하였고, 치료는 보다 복잡한 방법을 적용하였 으며, 치료 경과도 비교적 불량한 경우가 많았다.

본 연구에서의 턱관절 치료는 기본적인 상담과 약물치료, 장 치치료와 더불어, 온찜질, 냉각요법, 레이저 치료, ozonytron, EAST 등의 물리치료를 많이 활용 했다. 27 명의 환자들 중에서 17 명의 환자들에게 보존적인 처치만으로 턱관절 치료를 시행하 였고, 대부분 2 가지 이상의 복합된 치료가 이루어졌다. 보존적 인 처치에 효과를 보이지 않는 환자들은 적극적으로 정신건강 의학과, 재활의학과, 신경과, 마취통증의학과 등에 협진을 의뢰 하여 병행 치료를 시행하였고, 그럼에도 효과가 없거나, 그 이상 의 치료가 필요한 환자들에 한해서 선별적으로 비가역적인 치 료가 이루어졌다. 비가역적 치료는 관절강 내에 스테로이드나 히알루론산(hyaluronic acid) 주입을 한 경우는 7명, 보툴리눔 톡신을 저작근 및 측두근에 주입한 경우는 5명, 발통점 주사는 1 명, 관절강내시경을 이용한 세정술을 시행한 환자는 1 명이었 다. 대체로 보존적인 턱관절 치료에 효과를 보였다.

본 연구에서는 전체적으로 $63 \%$ 의 환자에게서 좋은 예후를 보 였으며 본원에 내원하는 일반적인 턱관절장애를 가진 환자들과 비교하면 다소 예후가 불량했다. 이는 정신적 질환을 가진 환자 들의 경우 의료진에 대한 협조도가 낮을뿐더러, 정신적 질환이 턱관절 질환을 심화시키는 요인으로 작용할 수 있기 때문이라 사료된다. RDC/TMD Axis II 자료는 환자의 정신적 지표를 평 가하는 도구이자 정신적, 사회적 상황을 확인하는 데 필요한 자 료로, 현재 구강안면통증 장애를 진단하는데 이용되고 있는 모 델이다[29]. 본 연구의 RDC/TMD Axis II를 분석한 자료에서는 만성통증 척도는 최근 6개월간 통증을 느낀 점수로 4점 만점에 평균 3.4로 큰 통증을 호소한다는 것을 확인 할 수 있었고, 우울 증 척도, 비특이성 신체 증상 척도에서도 마찬가지로 severe 하 다고 응답한 환자가 많았다. 하악 기능과 관련된 기능제한 점수 도 0.61점으로 높게 나타났다. 이처럼 정신적 문제가 개입되면 환자가 느끼는 주관적인 반응도 일반 턱관절 환자에 비해 높은 것을 알 수 있다.

Manfredini 등[30]은 턱관절장애 환자들에서 통증과 정신, 심 리적인 요소 사이에 밀접한 연관성이 있으며 정신적인 고통이 통증을 심화시킬 수 있기 때문에 근막성 통증과 턱관절 통증에 대하여 더욱 심화된 연구가 필요하다고 하였다. 본 연구에서는 타과와 함께 협진한 환자와 구강악안면외과 진료만 진행한 환 자들의 치료 경과에서 특별한 차이는 나지 않았지만, 구강악안 면외과 진료만으로 치료가 어려운 경우에 관련된 의과 협진을 시행하는 것이 장점이 많다고 생각된다. 반대로 정신건강의학 과나 신경과 치료 중인 환자들 중 턱관절장애 증상이 존재할 경 우 치과로 의뢰되어 협진하면 좋은 결과를 보일 것으로 예상된 다. 전반적인 환자의 수가 적어 통계적인 검증을 하기 어려운 점
이 이번 연구의 한계점으로 볼 수 있으며, 앞으로 정신적 질환을 가진 환자들 및 턱관절장애 환자들이 점점 늘어가는 추세에서 타 진료과와 상호 협력하는 복합적인 연구가 필요할 것으로 보 인다.

정신적 문제가 개입된 난치성 턱관절장애 환자들은 복잡하고 다양한 임상 증상들을 호소한다. RDC/TMD 설문, 병력 청취, 세심한 진찰을 통해 현재 턱관절 상태를 감별 진단해야 하며, 다 양한 임상증상들을 철저히 이해하여 상황에 맞게 선별적으로 보존적인 턱관절 치료들을 시행하는 것이 대체로 좋은 예후를 보여준다. 보존적인 턱관절 치료만으로 호전이 없거나, 더 효과 적인 턱관절 치료를 위해서는 신경과, 정신건강의학과, 마취통 증의학과, 재활의학과 등에 적극적인 협진을 의뢰하여 병행 치 료를 고려하는 것이 좋은 결과를 가져올 수 있다. 턱관절의 비가 역적인 치료는 그 이후에 고려해보는 것이 좋을 것으로 판단된 다.

\section{CONFLICTS OF INTEREST}

The authors declare that they have no competing interests.

\section{ORCID}

\author{
Dong-Woo Kang \\ https://orcid.org/0000-0002-0118-0053 \\ Young-Kyun Kim \\ https://orcid.org/0000-0002-7268-3870
}

\section{REFERENCES}

1. Carrara SV, Conti PCR, Barbosa JS. Statement of the 1st consensus on temporomandibular disorders and orofacial pain. Dent Press J Orthod 2010;15:114-120. doi: 10.1590/ S2176-94512010000300014.

2. Jung YW, Park SH, On SW, Song SI. Correlation between clinical symptoms and magnetic resonance imaging findings in patients with temporomandibular joint internal derangement. J Korean Assoc Oral Maxillofac Surg 2015;41:125-132. doi: 10.5125/jkaoms.2015.41.3.125.

3. Gonçalves DA, Dal Fabbro AL, Campos JA, Bigal ME, Speciali JG. Symptoms of temporomandibular disorders in the population: an epidemiological study. J Orofac Pain 2010;24:270-278.

4. Merskey H, Bogduk N. Classification of chronic pain: descriptions of chronic pain syndromes and definitions of pain terms. 2nd ed. Seattle: IASP Press; 1994. 244 p. 
5. Main CJ, Williams AC. Musculoskeletal pain. BMJ 2002;325:534-537. doi: 10.1136/bmj.325.7363.534.

6. Dworkin SF, LeResche L. Research diagnostic criteria for temporomandibular disorders: review, criteria, examinations and specifications, critique. J Craniomandib Disord 1992;6:301-355.

7. Crooks MC, Ferguson JW, Edwards JL. Clinical presentation and final diagnosis of patients referred to a temporomandibular joint clinic. N Z Dent J 1991;87:113118.

8. Ekberg E, Vallon D, Nilmer M. The efficacy of appliance therapy in patients with temporomandibular disorders of mainly myogenous origin. A randomized, controlled, shortterm trial. J Orofac Pain 2003;17:133-139.

9. Wahlund K, List T, Larsson B. Treatment of temporomandibular disorders among adolescents: a comparison between occlusal appliance, relaxation training, and brief information. Acta Odontol Scand 2003;61:203-211. doi: 10.1080/00016350310003891.

10. Clark GT. A critical evaluation of orthopedic interocclusal appliance therapy: design, theory, and overall effectiveness. J Am Dent Assoc 1984;108:359-364. doi: 10.14219/jada.archive.1984.0010.

11. Okeson JP. Bell WE. Harmon L. Bell's orofacial pains: the clinical management of orofacial pain. 6th ed. Carol Stream, IL: Quintessence Publishing; 2005.

12. Dionne RA. Pharmacologic treatments for temporomandibular disorders. Oral Surg Oral Med Oral Pathol Oral Radiol Endod 1997;83:134-142. doi: 10.1016/\$10792104(97)90104-9.

13. Dickstein R, Kafri M. Effects of antecedent TENS on EMG activity of the finger flexor muscles and on grip force. Somatosens Mot Res 2008;25:139-146. doi: 10.1080/ 08990220802131416.

14. Hong CZ. Lidocaine injection versus dry needling to myofasical trigger point. The importance of the local twitch response. Am J Phys Med Rehabil 1994;73:256-263. doi: 10.1097/00002060-199407000-00006.

15. Scicchitano J, Rounsefell B, Plilowsky I. Baseline correlates of the response to the treatment of chronic localized myofascial pain syndrome by injection of local anesthetic. J Psychosom Res 1996;40:75-85. doi: 10.1016/0022-3999 (95)00526-9.

16. Ahmed J, Binnal A, Rajan B, Denny C, Shenoy N. Ozone applications in dentistry: an overview. J Exp Integr Med 2013;3:171-176. doi: 10.5455/jeim.070513.rw.006.

17. Bocci V, Borrelli E, Travagli V, Zanardi I. The ozone paradox: ozone is a strong oxidant as well as a medical drug. Med Res Rev 2009;29:646-682. doi: 10.1002/med. 20150.

18. Kim HS, Yun PY, Kim YK. A clinical evaluation of botulinum toxin-A injections in the temporomandibular disorder treatment. Maxillofac Plast Reconstr Surg 2016;38:5. doi: 10.1186/s40902-016-0051-7.

19. Nitzan DW, Nitzan U, Dan P, Yedgar S. The role of hyaluronic acid in protecting surface-active phospholipids from lysis by exogenous phospholipase A(2). Rheumatolgy 2001;40:336-340. doi: 10.1093/rheumatology/40.3.336.

20. Kim SG. Necessity of standardized protocol for plateletrich plasma therapy in temporomandibular joint osteoarthritis. J Korean Assoc Oral Maxillofac Surg 2016; 42:65-66. doi: 10.5125/jkaoms.2016.42.2.65.

21. Yun PY, Kim YK. The role of facial trauma as a possible etiologic factor in temporomandibular joint disorder. J Oral Maxillofac Surg 2005;63:1576-1583. doi: 10.1016/ j.joms.2005.05.318.

22. Laskin DM. Arthrocentesis for the treatment of internal derangements of the temporomandibular joint. Alpha Omegan 2009;102:46-50. doi: 10.1016/j.aodf.2009.04.008.

23. Sorel B, Piecuch JF. Long-term evaluation following temporomandibular joint arthroscopy with lysis and lavage. Int J Oral Maxillofac Surg 2000;29:259-263. doi: 10.1016/S0901-5027(00)80024-7.

24. Ness GM, Laskin DM. Global doctor opinion versus a patient questionnaire for the outcome assessment of treated temporomandibular disorder patients. J Oral Maxillofac Surg 2012;70:1531-1533. doi: 10.1016/j.joms. 2011.11.015.

25. Ulmner M, Kruger-Weiner C, Lund B. Patient-specific factors predicting outcome of temporomandibular joint arthroscopy: a 6-year retrospective study. J Oral Maxillofac Surg 2017;75:1643.e1-1643.e7. doi: 10.1016/ j.joms.2017.04.005.

26. Kim YK, Kim SG, Im JH, Yun PY. Clinical survey of the patients with temporomandibular joint disorders, using research diagnostic criteria (Axis II) for TMD: preliminary study. J Craniomaxillofac Surg 2011 Jul 13 [Epub] http:// doi.org/10.1016/j.jcms.2011.05.018.

27. Schwartz RA, Greene CS, Laskin DM. Personality characteristics of patients with myofascial paindysfunction (MPD) syndrome unresponsive to conventional therapy. J Dent Res 1979;58:1435-1439. doi: 10.1177/00220345790580050101.

28. Celic R, Panduric J, Dulcic N. Psychologic status in patients with temporomandibular disorders. Int J Prosthodont 2006;19:28-29.

29. Shephard MK, Macgregor EA, Zakrzewska JM. Orofacial pain: a guide for the headache physician. Headache 2014; 54:22-39. doi: 10.1111/head.12272.

30. Manfredini D, Marini M, Pavan C, Pavan L, Guarda-Nardini L. Psychosocial profiles of painful TMD patients. J Oral Rehabil 2009;36:193-198. doi: 10.1111/j.1365-2842. 2008.01926.x. 